\title{
Role of glucagon-like peptide- 1 in the pathogenesis of experimental irritable bowel syndrome rat models
}

\author{
YAN CHEN ${ }^{*}$, ZHENGYANG LI* ${ }^{*}$ YAN YANG, LIN LIN and HONGJIE ZHANG \\ Department of Gastroenterology, The First Affiliated Hospital of Nanjing \\ Medical University, Nanjing, Jiangsu 210029, P.R. China
}

Received September 2, 2012; Accepted November 1, 2012

DOI: $10.3892 / \mathrm{ijmm} .2013 .1252$

\begin{abstract}
Alterations in gut motility and visceral hypersensitivity are two major features of irritable bowel syndrome (IBS). The aim of this study was to investigate the roles of glucagonlike peptide-1 (GLP-1) in the pathogenesis of experimental IBS. Rat models of constipation-predominant IBS (IBS-C) and diarrhea-predominant IBS (IBS-D) were established. Fecal water content and behavioral responses to colorectal distention (CRD), using electromyography (EMG), were measured. The expression of glucagon-like peptide-1 receptor (GLP-1R) in the colon was detected by immunohistochemistry, and the serum concentration of GLP-1 was measured by ELISA assay. The movement of circular and longitudinal colonic muscle was detected using an organ bath recording technique. Compared to controls, the fecal water contents were lower in the IBS-C group, while they were higher in the IBS-D group $(\mathrm{P}<0.05)$. EMG response to CRD in the experimental IBS groups was increased compared with their respective controls $(\mathrm{P}<0.05)$. GLP-1R was localized in the mucosa layer, circular muscle and myenteric nerve plexus of the colon. Notably, the expression of GLP-1R in the IBS-C group was higher, but in the IBS-D group, it was lower compared with controls. The serum levels of GLP-1 in the IBS-C group were higher compared to those in the IBS-D group $(\mathrm{P}<0.05)$. In addition, administration of exogenous GLP-1 and exendin-4 inhibited colonic circular muscle contraction, particularly in the IBS-C group, while there was no significant effect on longitudinal muscle contraction. In conclusion, these results indicated that GLP-1 and GLP-1R are implicated in the pathogenesis of IBS-C and IBS-D.
\end{abstract}

Correspondence to: Professor Lin Lin or Professor Hongjie Zhang, Department of Gastroenterology, The First Affiliated Hospital of Nanjing Medical University, 300 Guangzhou Road, Nanjing, Jiangsu 210029, P.R. China

E-mail: lin9100@yahoo.com.cn

E-mail: hjzhang06@163.com

*Contributed equally

Key words: irritable bowel syndrome, glucagon-like peptide-1, visceral hypersensitivity, glucagon-like peptide-1 receptor, gastrointestinal motility

\section{Introduction}

Irritable bowel syndrome (IBS) is a chronic, functional gastrointestinal disorder affecting approximately $10-15 \%$ of the world's population. It is characterized by abdominal pain and discomfort and altered bowel habits (1-3). According to bowel habits, IBS is classified into four subgroups: IBS with diarrhea (IBS-D), IBS with constipation (IBS-C), mixed IBS (IBS-M), and untyped IBS (IBS-U) (4,5). Alterations in gut motility and visceral hypersensitivity are two main features of IBS. IBS-associated abdominal pain is believed to result from smooth muscle activity disorder and visceral hypersensitivity (6).

The glucagon-like peptide-1 (GLP-1) analogue ROSE-010 has been found to relieve abdominal pain in patients with IBS (7). GLP-1 is an incretin hormone secreted from L-cells in response to ingested nutrients (8). GLP-1 decreases gastrointestinal motility and gastric emptying in healthy subjects and rodents (9-13). GLP-1 also decreases motility in the antro-duodeno-jejunal region and inhibits the migrating motor complex (MMC) in IBS patients (9). Moreover, GLP-1 exerts inhibitory effects on gastrointestinal motility, not only through vagal afferents and central nervous mechanisms, but also through a peripheral motor action mechanism (14).

The expression of GLP-1 receptors (GLP-1R) has been detected in human small and large intestines (15). In the present study, we aimed to investigate the role of GLP-1 and its receptor in the pathogenesis of experimental IBS rat models by detecting the serum level of GLP-1 and the expression of GLP-1R in the gut. The effect of GLP-1 on circular smooth muscle and longitudinal muscle responses of intestinal segments was also assessed.

\section{Materials and methods}

Animals. Fifty adult male Sprague-Dawley rats (200-220 g) were obtained from Beijing Vital River Laboratories Animal Technology Co., Ltd., and were divided into five groups: IBS-C group $(n=10)$; IBS-C control group $(n=10)$; IBS-D group $(n=10)$; IBS-D control group $(n=10)$; and a blank control group $(n=10)$. IBS-C rats were pretreated with $0-4^{\circ} \mathrm{C}$ cool water $(2 \mathrm{ml})$ to irrigate the stomach daily for 14 days (16). The IBS-C control rats were treated with normal drinking water ( $2 \mathrm{ml})$. IBS-D rats were established by wrap restraint stress as described by Williams et al (17) with slight modifications. The IBS-D control rats were given sham restraint stress. Rats 
were given free access to standard rat chow (GB14924.3-2001, China) and water, and they were acclimated for at least 7 days before experiments. The protocol was approved by the Animal Use and Care Committee of Nanjing Medical University.

Water content of feces. The rats of each group were placed in separate cages for $3 \mathrm{~h}$, and the amount and weight of the feces expelled by each rat were collected and recorded during this time period. The feces dried in an oven were weighed again. Water content of the feces was calculated by the following formula: Water content $\%=$ [wet weight of the feces $(\mathrm{g})$ - dried weight of the feces $(\mathrm{g})] /$ wet weight of the feces $(\mathrm{g}) \times 100 \%(18)$.

Small intestine transit rate. After fasting for $12 \mathrm{~h}$, each rat received $2 \mathrm{ml}$ of $2 \%$ India ink by gavage. Rats were rapidly euthanized and the small intestine samples from the pylorus to the cecum were removed $30 \mathrm{~min}$ after receiving India ink. The percentage of small intestine transit was defined as: small intestine transit rate $\%=$ the promoting length of the ink $(\mathrm{cm}) /$ the total length of intestine (cm) x100\% (19).

Visceromotor response. Behavioral responses to colorectal distention (CRD) were assessed by a measurement of the electromyogram (EMG) activity of the external oblique (20). Seven days prior to the experiment, stainless steel EMG electrodes were implanted into the lateral abdominal wall of the rats, and the electrode leads were exteriorized at the back of the neck. On the day of the experiment, rats were sedated with isofluorane, and a flexible balloon $(5 \mathrm{~cm})$ constructed from a surgical glove finger attached to a catheter was inserted into the descending colon and rectum via the anus; the catheter was fixed to the base of the tail. Rats were placed in small Lucite cubicles $(20 \times 8 \times 8 \mathrm{~cm})$ (Medical Instrument Co., Ltd., Zhejiang, China). After the rats were fully awake and acclimatized, CRD was performed. Each trial consisted of graded intensity stimulation trials $(0,20,40$ and $60 \mathrm{mmHg})$ for a 20 -sec stimulation period followed by a 2-min rest, and then the procedure was repeated one more time (21). The EMG was recorded continuously during the experiment on an EMG measurement system (Power Labs, Australia). The maximum amplitude of the curve for the EMG signal was calculated.

Sample preparation. Blood samples and the colon tissue samples were collected for RNA extraction, western blotting. Colonic muscle strips were made for the smooth muscle contraction experiment. The colon tissue sections were used for hematoxylin and eosin (H\&E) staining, immunohistochemistry. H\&E-stained sections were scored for colonic inflammation in model rats as previously described (22).

GLP-1R immunohistochemistry. The sections were incubated with anti-GLP-1R antibody (AB-39072; Abcam) at a final dilution of 1:100 for $24 \mathrm{~h}$ at $4^{\circ} \mathrm{C}$. The immunoreaction was revealed by using horseradish peroxidase (HRP)-labeled secondary mouse anti-rabbit antibody (1:500; Jingmei Biological Engineering Co., Ltd., Shenzhen, China) for $2 \mathrm{~h}$ at room temperature. The slides were mounted and scanned using a microscope (Olympus, Tokyo, Japan). Five high power fields $(\mathrm{x} 400)$ from each slide were randomly selected for analysis using Image-Pro Plus image analysis software. The average optical density value represents the relative expression of proteins.

Quantitative real-time PCR. GLP-1R gene expression in the colon was analyzed by quantitative real-time polymerase chain reaction (qRT-PCR). Total RNA was extracted using TRIzol (Invitrogen, Carlsbad, CA, USA). One microgram of total RNA was reverse-transcribed in a final volume of $50 \mu \mathrm{l}$ using the ABI PRISM cDNA Archive kit. $\beta$-actin and GLP-1R were amplified using $5 \mu \mathrm{l}$ of cDNA per reaction. The primers and TaqMan fluorogenic probes were purchased from Invitrogen. $\beta$-actin was used as an internal gene. The primers for rat GLP-1R and $\beta$-actin were as follows: GLP-1R, forward, 5'-CA TCGTGGTATCCAAACTGA-3' and reverse, 5'-GCTCGTCC ATCACAAAGG-3'; $\beta$-actin, forward, 5'-TATGACTTAGTTG CGTTACACC-3' and reverse, 5'-CCTTCACCGTTCCAGT TT-3'. The amplification reaction was performed in an ABI PRISM 7500 fluorescence quantitative PCR instrument using the following conditions: $50^{\circ} \mathrm{C}$ for $2 \mathrm{~min}, 95^{\circ} \mathrm{C}$ for $10 \mathrm{~min}$ and $95^{\circ} \mathrm{C}$ for $15 \mathrm{sec}$, and a final extension step of $1 \mathrm{~min}$ at $66^{\circ} \mathrm{C}$, 40 cycles, stored at $4^{\circ} \mathrm{C}$. The data were analyzed by the relative gene expression, which was determined using the $2^{-\Delta \Delta}$ cycle threshold (Ct) method (23).

Western blotting. A colon tissue sample $(100 \mathrm{mg})$ was homogenized in a buffer containing $25 \mathrm{mM}$ Tris- $\mathrm{HCl}(\mathrm{pH} 7.5), 5 \mathrm{mM}$ EDTA, $5 \mathrm{mM}$ EGTA, $0.5 \mathrm{mM}$ PMSF, $25 \mu \mathrm{g} / \mathrm{ml}$ leupeptin, $10 \mu \mathrm{g} / \mathrm{ml}$ aprotinin, and $1 \mathrm{mM}$ sodium vanadate. The crude protein homogenates with sample buffer were boiled for 5 min. Samples were subjected to $10 \%$ sodium dodecyl sulfate polyacrylamide gel electrophoresis (10 mg/lane) and then transferred to a polyvinylidene difluoride membrane for immunoblotting. The membranes were incubated in blocking buffer (5\% non-fat milk in Tween/Tris-buffered salt solution, TTBS) containing anti-GLP-1R antibody (1:400; Abcam Ltd.). Following multiple washes, the membranes were incubated for $1.5 \mathrm{~h}$ at room temperature with secondary antibody $(1: 1,000)$ linked to horseradish peroxidase (HRP). The immunopositive proteins on the membrane were detected by an enhanced chemiluminescence detection kit (ECL; Millipore, Bedford, MA, USA). The target band and the band for $\beta$-actin were quantified by the Tianneng GIS gel image processing system for optical density analysis.

Detection of serum GLP-1 levels by ELISA. The blood samples were collected and DPP-4 inhibitor (Millipore) was added to the blood samples. Following centrifugation at $4,000 \mathrm{x}$ g for $10 \mathrm{~min}$ at $4{ }^{\circ} \mathrm{C}$, the supernatants were stored at $-20^{\circ} \mathrm{C}$ until detection. The serum level of GLP-1 (7-36) was measured by ELISA (Linco Research Inc.). An aliquot of $100 \mu$ l of each sample was added to each assay well. ELISA has a working range of 2-100 pM.

Validation of the effects of GLP-1 and its receptor agonists on rat colon circular and longitudinal muscle strips in rat models of IBS-C and IBS-D. The muscle strips obtained by cutting along the longitudinal axis of the colon were the longitudinal muscle strips $(2 \times 10 \mathrm{~mm})$, and along the circular axis were the circular muscle strips $(2 \times 10 \mathrm{~mm})$, as previously reported (24). The muscle strips were suspended in a designed horizontal organ bath, which contained $10 \mathrm{ml}$ of Krebs solution, continu- 
A
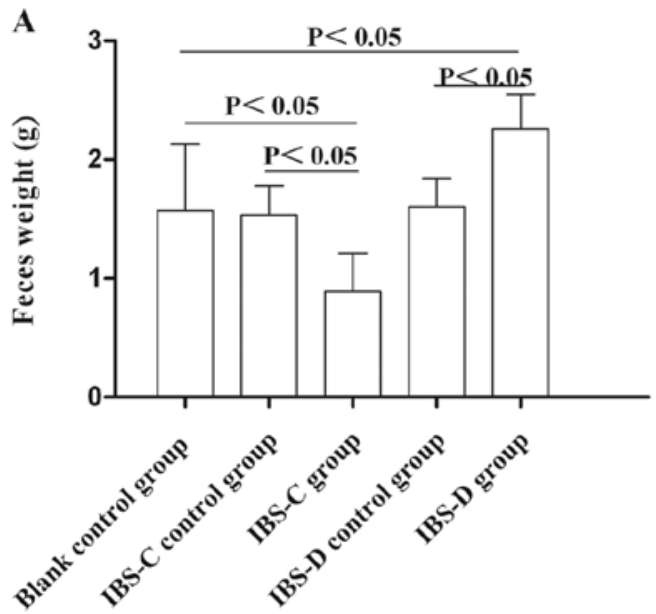

B
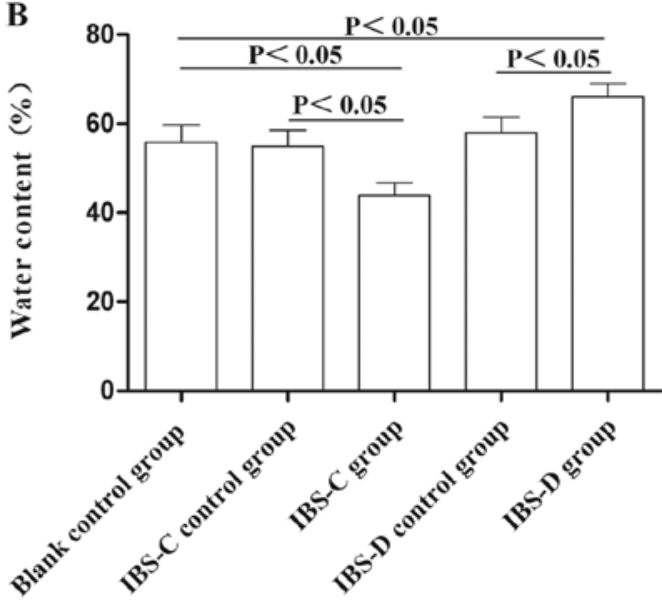

Figure 1. Weight and water content of the feces in experimental IBS-C and IBS-D. (A) The weight of fecal pellets in a 3-h restraint stress period in IBS-C and IBS-D model groups. The weight of fecal pellets in the IBS-C group was lower compared with its control groups $(\mathrm{P}<0.05)$, while the weight of fecal pellets in the IBS-D group was higher compared with its control groups $(\mathrm{P}<0.05)$. (B) The water content of the feces in a 3-h restraint stress period in the IBS-C and IBS-D groups. Compared with control groups $(\mathrm{P}<0.05)$, the water content of the feces in the IBS-C group was significantly less, while it was significantly higher in the IBS-D group. IBS-C group, constipation-predominant experimental IBS group; IBS-D group, diarrhea-predominant experimental IBS group.

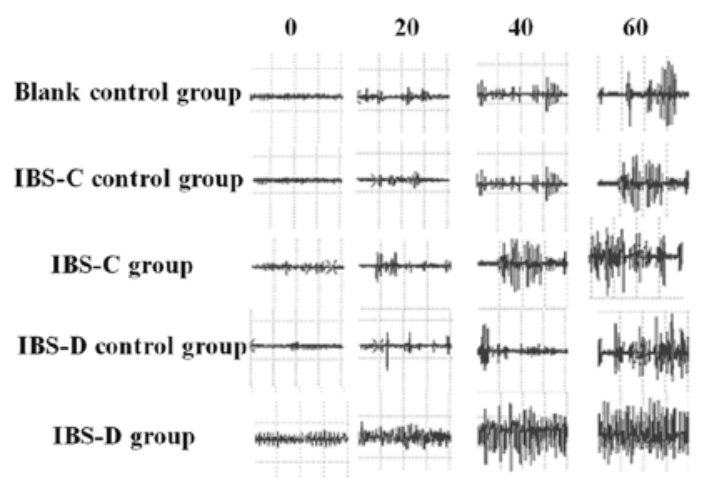

Pressure $(\mathrm{mmHg})$

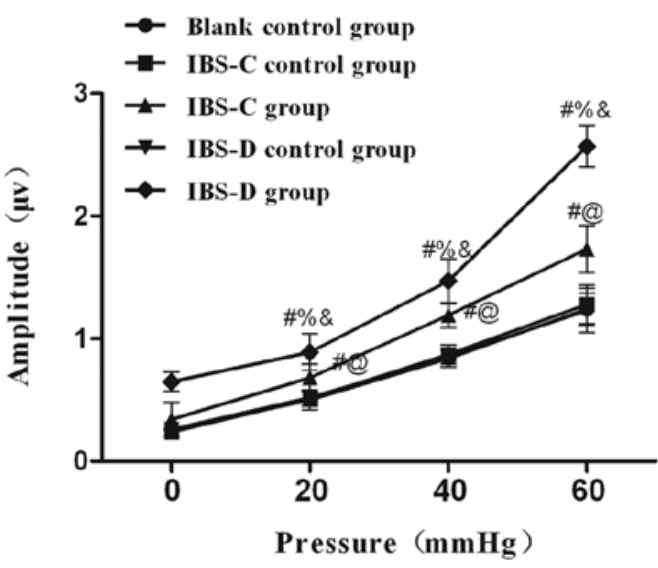

Pressure $(\mathrm{mmHg})$

Figure 2. Magnitude of visceromotor response to colorectal distention (CRD) in experimental IBS-C and IBS-D. Left, typical electromyography (EMG) tracings of the five groups. Right, EMG tracings show that the rats in the IBS-C and IBS-D groups exhibited higher mean amplitudes at 20,40 and $60 \mathrm{mmHg}$, compared with control groups $(\mathrm{P}<0.05)$. The mean amplitudes in the IBS-D group were markedly higher than those in the IBS- $\mathrm{C}$ group at 20,40 and $60 \mathrm{mmHg}$ $\left({ }^{\sharp} \mathrm{P}<0.05\right.$ vs. the blank control group; ${ }^{\%} \mathrm{P}<0.05$ vs. the IBS-D control group; ${ }^{\circledR} \mathrm{P}<0.05$ vs. the IBS-C group; ${ }^{\circledR} \mathrm{P}<0.05$ vs. the IBS-C control group). IBS-C group, constipation-predominant experimental IBS group; IBS-D group, diarrhea-predominant experimental IBS group.

ously perfused with a $95 \% \mathrm{O}_{2}$ and $5 \% \mathrm{CO}_{2}$ mixture, and heated $\left(37^{\circ} \mathrm{C}\right)$ in Krebs solution with the following composition: $119 \mathrm{mM} \mathrm{NaCl}, 4.5 \mathrm{mM} \mathrm{KCl}, 2.5 \mathrm{mM} \mathrm{MgSO}_{4}, 25 \mathrm{mM} \mathrm{NaHCO}_{3}$, $1.2 \mathrm{mM} \mathrm{KH}_{2} \mathrm{PO}_{4}, 2.5 \mathrm{mM} \mathrm{CaCl}_{2}$, and $11.1 \mathrm{mM}$ glucose, $\mathrm{pH}$ 7.4. One end of each strip was fixed to organ holders, and the other end was fastened by a silk tie to an isometric tension transducer (National Institute for Physiology, Japan). Each muscle strip was slowly stretched at an initial tension of $0.5 \mathrm{~g}$ and allowed to equilibrate for $60 \mathrm{~min}$ to reach a steady baseline before experiments. Then, saline, GLP-1, and exendin- 4 were added, respectively, and the effects of these peptides on the IBS subtypes and matched controls were evaluated. After the addition of GLP-1 and exendin-4, respectively, the contraction curve was recorded within $5 \mathrm{~min}$. The peptides were then eluted in the bath, and the next trial was not performed until the smooth muscle strips were restored to a steady state. We took the area under the curve (AUC) of saline as 100\%: data were expressed as the percentage of the AUC obtained in the presence of saline on the ACh pretreated muscle strips. Mechanical signals from each strip were amplified with an amplifier, recorded, and analyzed using Med Lab 6.0 software (MedEase, Nanjing, China).

Statistical analysis. Data are presented as the means \pm SD. Analyses were performed using SPSS 13.0 software (Jandel Scientific-SPSS Science, Chicago, IL, USA). The IBS subtypes and control groups were compared, and data were analyzed using one-way ANOVA followed by Bonferroni post-test comparisons. $\mathrm{P}<0.05$ was considered to indicate statistically significant differences.

\section{Results}

Feces changes in experimental IBS-C and IBS-D rat models. To validate the successful establishment of rat models of IBS-C and IBS-D, water content of the feces and feces weight in the experimental IBS models were measured. The fecal pellets in 


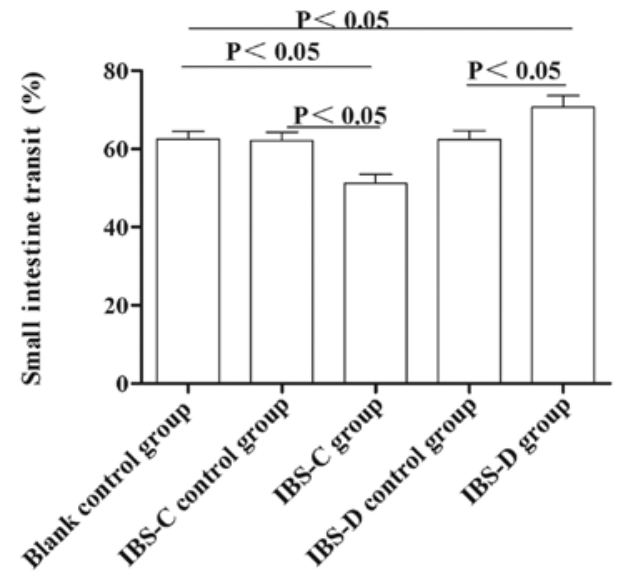

Figure 3. Changes of small intestine transit rate in experimental IBS-C and IBS-D. The small intestine transit rate for the experimental IBS-C group was slower than its matched control groups. However, for the experimental IBS-D group, it was faster than its matched control groups. Small intestine transit rate $\%=$ the promoting length of the ink $(\mathrm{cm}) /$ the total length of intestine (cm) $\times 100 \%$. IBS-C group, constipation-predominant experimental IBS group; IBS-D group, diarrhea-predominant experimental IBS group. the IBS-C group weighed less than those in the control group $(\mathrm{P}<0.05)$; the fecal pellets in the IBS-D group weighed more than those in the control group $(\mathrm{P}<0.05)$ (Fig. 1). In addition, the water content of the feces in the IBS-C rats was significantly less, and water content in the feces of IBS-D rats was significantly more compared with the control rats $(\mathrm{P}<0.05)$ (Fig. 1). These results suggested that the models of IBS-C and IBS-D were established successfully.

Visceromotor responses in experimental IBS rat models. A significant increase in the maximum amplitude curve of the EMG in response to increased CRD pressure in both experimental IBS rats was detected (Fig. 2). The mean amplitudes in both IBS-C and IBS-D rats exhibited higher responses to different distention pressures compared with their matched controls, respectively. These data indicated that the IBS model groups were more sensitive to CRD compared with controls, suggesting that gastric instillation of cool saline and wrap restraint stress produced a persistent visceral hypersensitivity in IBS-C and IBS-D rats.

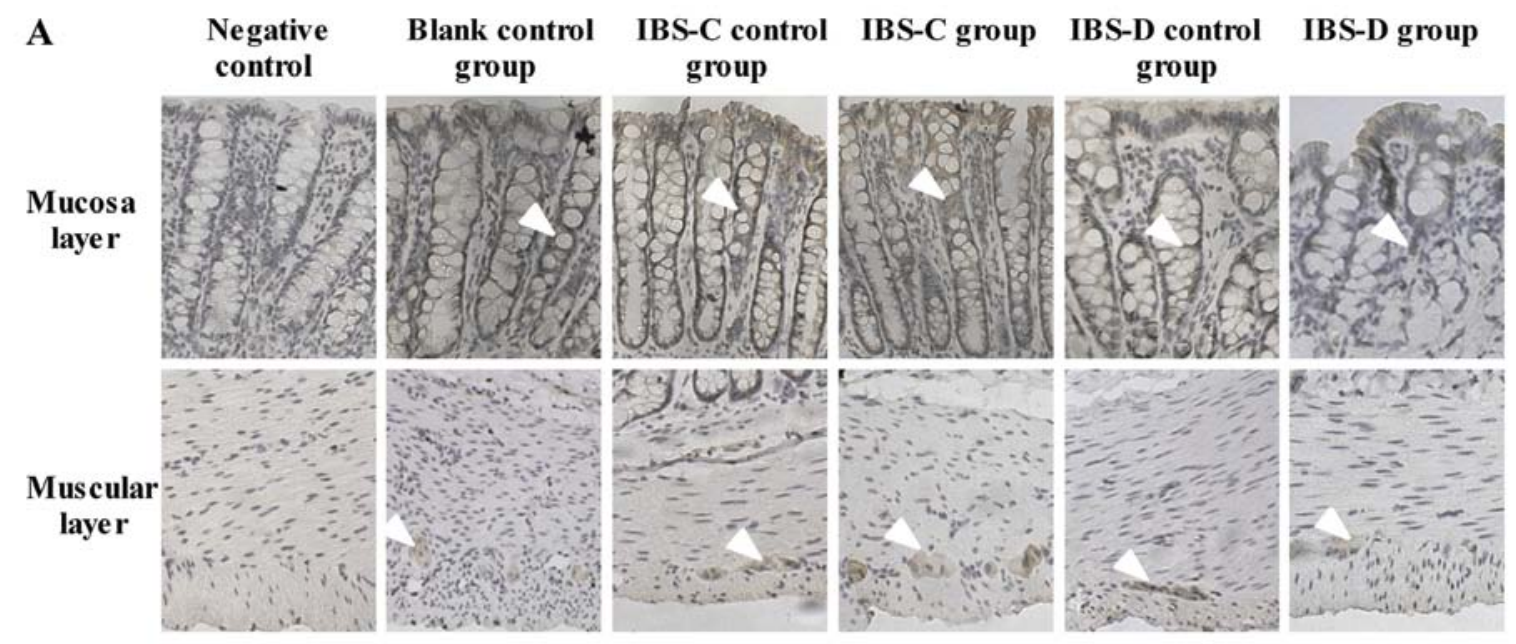

B

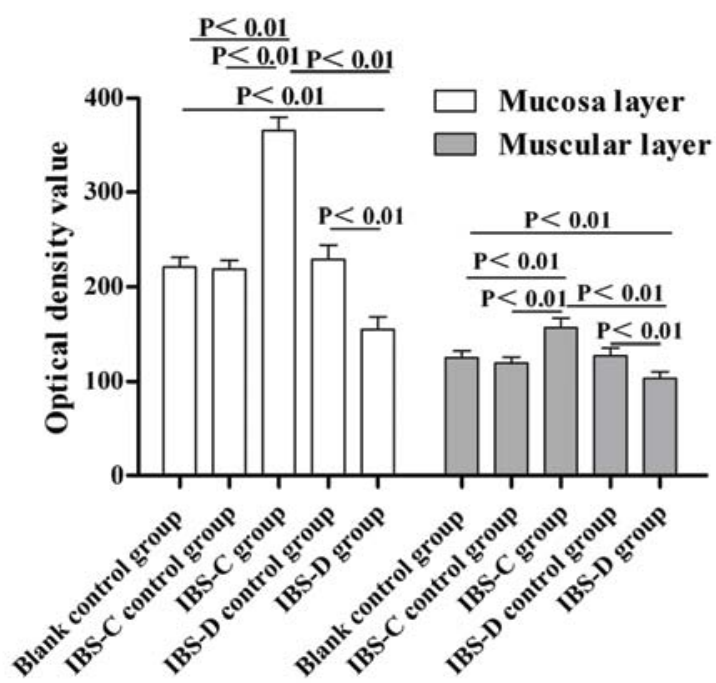

Figure 4. Immunohistochemical assessment of GLP-1R expression in experimental IBS-C and IBS-D. (A) GLP-1R immunoreactivity was observed in the colon mucosa layer and circular muscle and myenteric plexus of all samples (arrows). (B) GLP-1R in the experimental IBS-C group was higher than that in its control groups and the IBS-D group ( $\mathrm{P}<0.01$ vs. the IBS-C control and the blank control group). On the contrary, GLP-1R immunoreactivity in the IBS-D group was significantly lower than that in the control groups $(\mathrm{P}<0.01$ vs. the IBS-D control and the blank control group). IBS-C group, constipation-predominant experimental IBS group; IBS-D group, diarrhea-predominant experimental IBS group. 
A

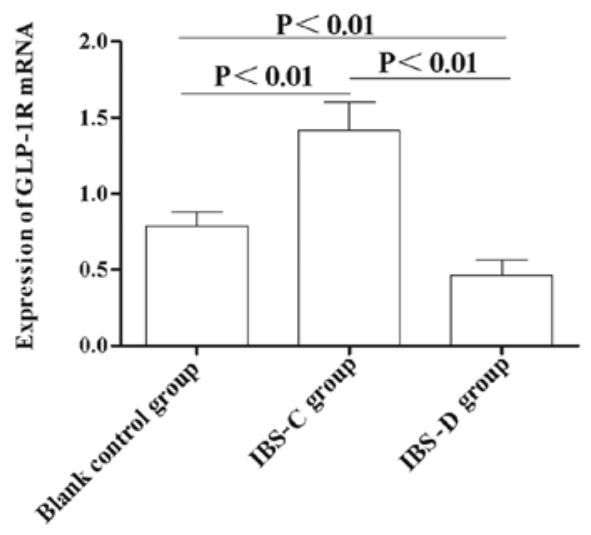

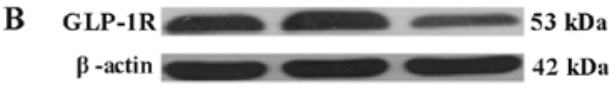

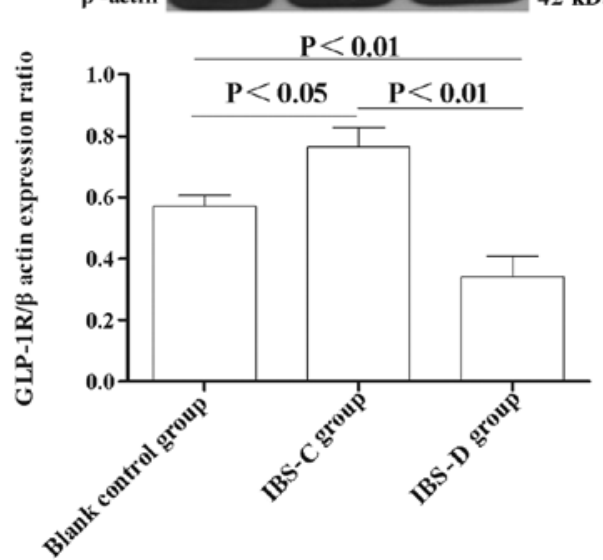

Figure 5. Expressions of GLP-1R mRNA and protein in experimental IBS-C and IBS-D colons. (A) Expression of GLP-1R transcript levels was significantly higher in the colon from experimental IBS-C rats compared with control groups $(\mathrm{P}<0.01)$ and the experimental IBS-D group $(\mathrm{P}<0.01)$. (B) Representative western blot analyses for GLP-1R (upper panel) and $\beta$-actin (lower panel) for rat colon from experimental IBS subtypes in comparison with control; the GLP-1R protein level was also higher in the experimental IBS-C group, compared with the control and experimental IBS-D group (P<0.01). IBS-C group, constipation-predominant experimental IBS group; IBS-D group, diarrhea-predominant experimental IBS group.

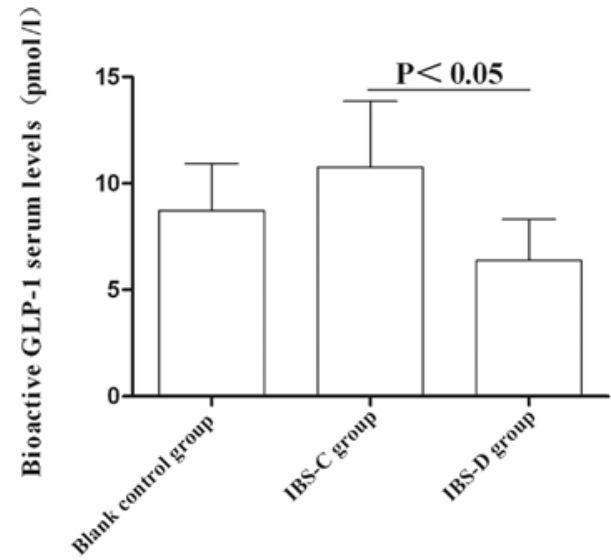

Figure 6. Bioactive GLP-1 serum levels in experimental IBS-C and IBS-D. The average serum level of GLP-1 in the IBS-C group was significantly higher than in the IBS-D group $(\mathrm{P}<0.05)$. There were no significant differences between the experimental IBS groups and the blank control group $(\mathrm{P}>0.05)$. IBS-C group, constipation-predominant experimental IBS group; IBS-D group, diarrhea-predominant experimental IBS group.

Small intestine transit rate in experimental IBS rat models. To observe the motility changes in experimental IBS-C and IBS-D in vivo, we measured the small intestine transit rate. As shown in Fig. 3, the small intestine transit rate in IBS-C rats was lower than that in IBS controls and blank controls (51.17 \pm 2.32 vs. $62.09 \pm 2.22, \mathrm{P}<0.05$ and $62.60 \pm 1.89, \mathrm{P}<0.05$, respectively). In IBS-D rats, the small intestine transit rate was higher compared with that in IBS-D controls and blank controls $(70.69 \pm 2.91$ vs. $62.39 \pm 2.31, \mathrm{P}<0.05$ and $62.60 \pm 1.89$, $\mathrm{P}<0.05$, respectively). These results suggested that small intestine transit in IBS-D rats was accelerated, while the small intestine transit in IBS-C was delayed, compared with their controls, respectively.

Expression of GLP-1R in the colon. To study the GLP-1 signaling implication in IBS, we investigated the expression changes of GLP-1R in experimental IBS-C and IBS-D.
Immunohistochemistry results showed that GLP-1R immunoreactivity was mainly located in the colonic mucosa layer and in the circular muscle and myenteric plexus in both experimental IBS rats (Fig. 4A). Markedly, the expression of GLP-1R in the IBS-C group was higher than that in its control group $(\mathrm{P}<0.01)$ (Fig. 4B). By contrast, the expression of GLP-1R in the IBS-D group was significantly lower than that in its matched control $(\mathrm{P}<0.01)$ (Fig. 4B). Furthermore, the GLP-1R expression in the IBS-C group was much higher than that in the IBS-D group $(\mathrm{P}<0.01)$ (Fig. 4B).

qRT-PCR analysis showed that the expression of GLP-1R mRNA level in the IBS-C group was significantly higher compared with the control group $(\mathrm{P}<0.01)$ (Fig. 5A), while in the IBS-D group, the GLP-1R mRNA level was significantly lower compared with the matched control $(\mathrm{P}<0.01)$ (Fig. 5A). Moreover, the GLP-1R protein level was also significantly higher in the IBS-C group compared with the control group $(\mathrm{P}<0.01)$ (Fig. 5B), while the GLP-1R level the IBS-D group was significantly lower than that in the control group $(\mathrm{P}<0.01)$ (Fig. 5B). These results indicated that abnormal GLP-1R expression is involved in the pathogenesis of IBS.

Circulating GLP-1 levels. The average serum level of GLP-1 in the IBS-C group was significantly higher than that in the IBS-D group $(10.76 \pm 3.1$ vs. $6.37 \pm 1.93 \mathrm{pM}, \mathrm{P}<0.05)$. However, no significant difference of serum GLP-1 level was detected between these two IBS subtype models and control group (P>0.05) (Fig. 6). These results suggested that GLP-1 may be involved in IBS subtype formation.

Effects of GLP-1 and its receptor agonists on colon muscle strips in experimental IBS rat models. To determine the involvement of GLP-1 in the pathogenesis of IBS, we tested the responses of colon muscle strips to GLP-1 and exendin- 4 . Following pretreatment of muscle strips with $\mathrm{ACh}$, the optimal concentration of GLP-1 $\left(1.0 \times 10^{-7} \mathrm{M}\right)$ or exendin- $4\left(8.0 \times 10^{-8} \mathrm{M}\right)$ was added. We found that GLP-1 and exendin-4 had no effect on Ach-pretreated longitudinal muscle strips (Fig. 7B), while 
A
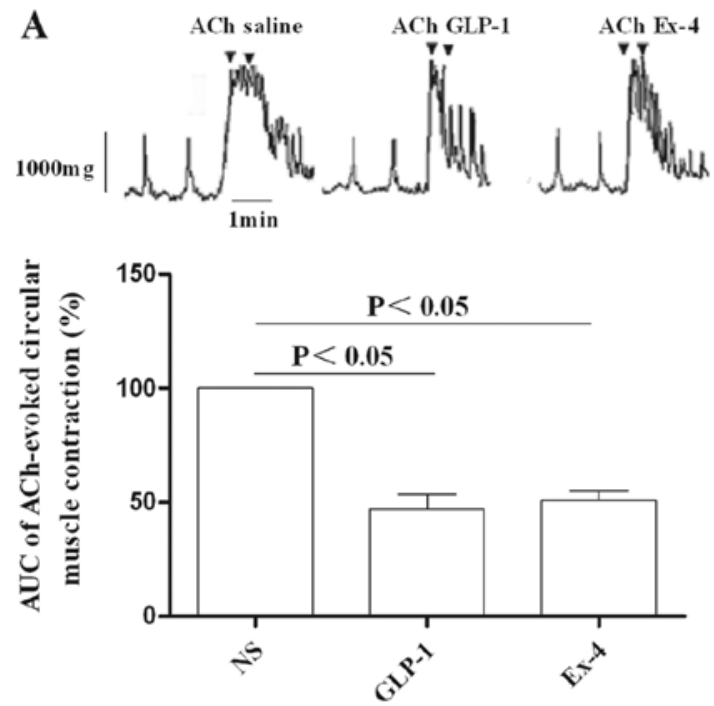

C

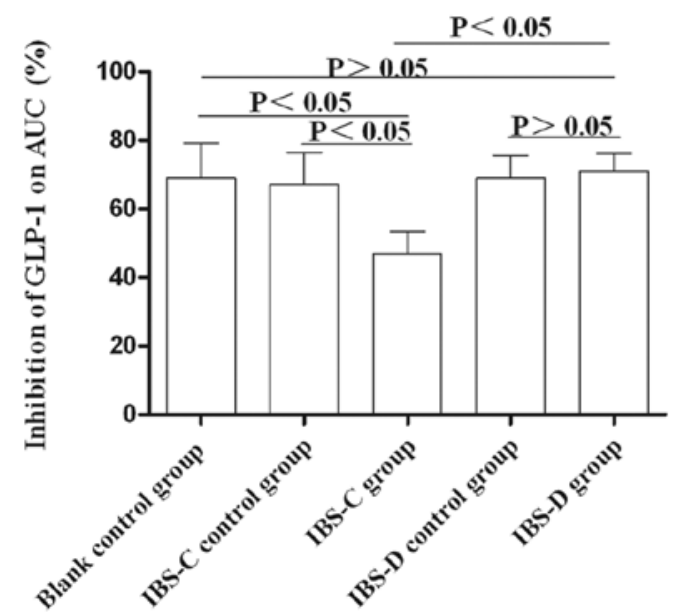

B

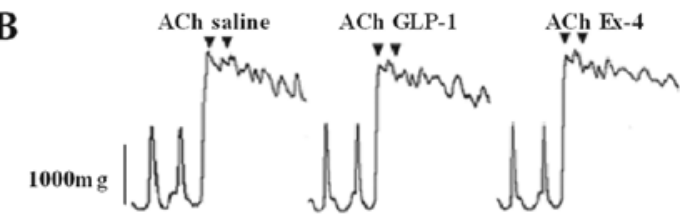

$\overline{1 \mathrm{~min}}$

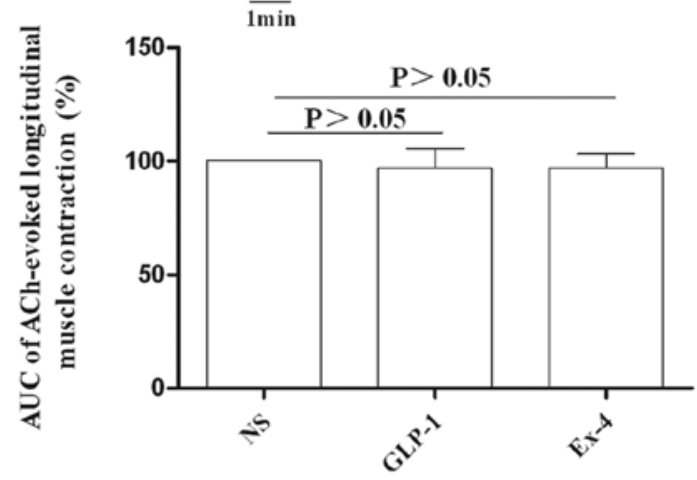

D

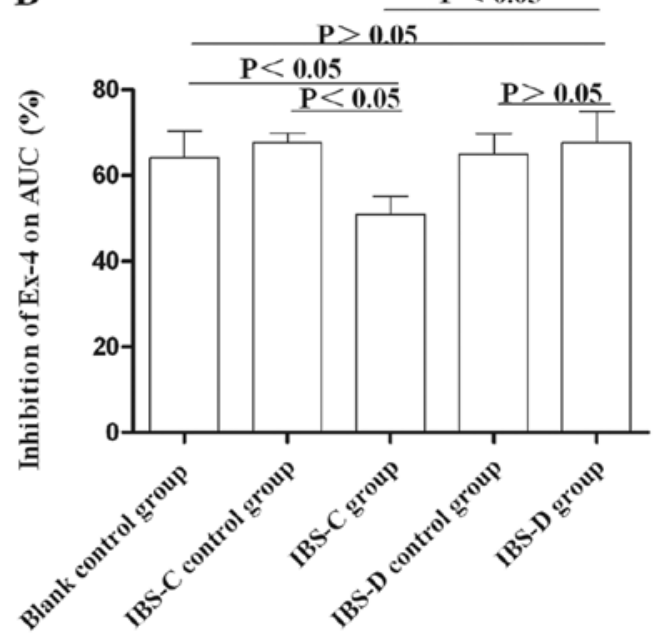

Figure 7. Effect of GLP-1 and its receptor agonist on colon muscle strips of experimental IBS-C and IBS-D. Representative recordings show the inhibitory effects of GLP-1 and exendin-4 on Ach-pretreated circular muscle (upper trace A) but not on Ach-pretreated longitudinal muscle (upper trace B). (A) GLP-1 and its receptor agonist had inhibitory effects on Ach-precontracted circular muscle strips. (B) GLP-1 and its receptor agonist had no effect on Ach-precontracted longitudinal muscle strips. (C) Inhibition by GLP-1 on Ach-precontracted circular muscle strips in the experimental IBS-C group was the most powerful compared with the control groups and experimental IBS-D group $(\mathrm{P}<0.05)$. (D) Inhibition by exendin-4 on Ach-precontracted circular muscle strips in the experimental IBS-C group was the most powerful. IBS-C group, constipation-predominant experimental IBS group; IBS-D group, diarrhea-predominant experimental IBS group.

they exerted inhibitory effects on Ach-pretreated circular muscle strips in both experimental IBS models and control groups (Fig. 7A). Furthermore, the inhibition by GLP-1 or exendin-4 on Ach-pretreated circular muscle strips in the IBS-C group was more obvious compared to that in the IBS-D group $(\mathrm{P}<0.05)$ (Fig. 7C and $\mathrm{D})$.

\section{Discussion}

In recent years, several different animal models of IBS have been established to investigate the pathogenesis and treatment of IBS. However, so far there has not been a perfect model imitating the clinical manifestations of IBS patients. In our study, the IBS-C group was established by gastric instillation of $0-4^{\circ} \mathrm{C}$ saline daily for 14 days (16), and the IBS-D group was established by wrap restraint stress (17). The IBS-D rats showed visceral hypersensitivity and defecated more stool compared with the control rats, which was in accordance with the clinical observations in IBS-D patients. Regarding the IBS-C model, no marked inflammation was found in the colon after gastric instillation with $0-4^{\circ} \mathrm{C}$ cool water daily for 14 days. Compared with the blank control, the amount, weight, and water content of the feces expelled by the IBS-C rats were significantly less, and the time before the first black stool occurred in the IBS-C group was significantly longer than that in the control groups.

Previous studies found that GLP-1 can slow gastric emptying and inhibit intestinal movement (25-27). A clinical case report (28) indicated that a patient with a neuroendocrine tumor who had high serum levels of GLP-1 (300 to 400-fold) had markedly delayed gastrointestinal transit and severe intractable constipation. Normal bowel function was restored after tumor resection. This indicates that GLP-1 is involved in the formation of constipation, but the underlying mechanism remains unclear. Our observations showed that the serum bioac- 
tive GLP-1 level in the IBS-C group was higher compared with the control group, which indicates that an increased bioactive GLP-1 level may be related to the formation of constipation in experimental rats. In addition, our results showed that exogenous GLP-1 and its receptor agonist, exendin-4, can effectively inhibit colon circular muscle contraction in a rat experimental IBS model, while having no effect on longitudinal muscle contraction. These results can be explained by the fact that GLP-1R was located in the circular muscle and myenteric neurons, while no GLP-1R-positive staining was detected in the longitudinal muscle. These results are consistent with the report of Amato et al (14), who showed that GLP-1R was detected in some myenteric neurons in rats, and GLP-1 regulated the release of NO to decrease the excitatory cholinergic neurotransmission by acting on the presynaptic GLP-1Rs, and then inhibited the intestinal movement.

As circular muscle contraction is dominant in peristalsis, the action of GLP-1 could contribute to the reduction of intestinal transit (14). In our study, GLP-1 and its receptor agonist inhibited rat colonic circular muscle, particularly in the IBS-C group, suggesting that the high serum levels of GLP-1 and high expression of GLP-1R in the IBS-C group inhibited colonic movement to cause the dry stool and sluggish rat small intestine transit, leading to constipation. In summary, GLP-1 and its receptors may be involved in altered gastrointestinal motility in the pathogenesis of IBS.

The gastrointestinal mucosa may receive a variety of stimuli to impart various types of signals to the central nervous system and lead to sensory dysregulation. Our results showed that GLP-1R is mainly expressed in the colon mucous layer, and its expression varied among the experimental IBS subtypes, indicating that GLP-1 and GLP-1R might be related to the formation of visceral hypersensitivity in IBS models; however, this requires further investigation.

In conclusion, our results showed that GLP-1 and GLP-1R altered gastrointestinal motility of experimental IBS-C and IBS-D, suggesting a potentially important role for GLP-1 and GLP-1R in IBS-C and IBS-D and motility dysfunction.

\section{Acknowledgements}

This study was supported by grants from the National Natural Science Foundation of China (no. 30771039) and the Key Medical Personnel of Jiangsu Province (no. RC2011063)

\section{References}

1. Drossman DA: The functional gastrointestinal disorders and the Rome III process. Gastroenterology 130: 1377-1390, 2006.

2. Clarke G, Quigley EM, Cryan JF and Dinan TG: Irritable bowel syndrome: towards biomarker identification. Trends Mol Med 15: 478-489, 2009

3. Cremonini F and Talley NJ: Irritable bowel syndrome: epidemiology, natural history, health care seeking and emerging risk factors. Gastroenterol Clin North Am 34: 189-204, 2005.

4. Spiller RC and Thompson WG: Bowel disorders. Am J Gastroenterol 105: 775-785, 2010.

5. Longstreth GF, Thompson WG, Chey WD, Houghton LA, Mearin F and Spiller RC: Functional bowel disorders. Gastroenterology 130: 1480-1491, 2006

6. Camilleri M, McKinzie S, Busciglio I, et al: Prospective study of motor, sensory, psychologic, and autonomic functions in patients with irritable bowel syndrome. Clin Gastroenterol Hepatol 6: 772-781, 2008.
7. Hellstrom PM, Hein J, Bytzer P, Bjornsson E, Kristensen J and Schamby H: Clinical trial: the glucagon-like peptide-1 receptor agonist ROSE-010 for management of acute pain in patients with irritable bowel syndrome: a randomized, placebo-controlled, double-blind study. Aliment Pharmacol Ther 29: 198-206, 2009.

8. Elliott RM, Morgan LM, Tredger JA, Deacon S, Wright J and Marks V: Glucagon-like peptide-1 (7-36)amide and glucosedependent insulinotropic polypeptide secretion in response to nutrient ingestion in man: acute post-prandial and 24-h secretion patterns. J Endocrinol 138: 159-166, 1993.

9. Hellstrom PM, Naslund E, Edholm T, et al: GLP-1 suppresses gastrointestinal motility and inhibits the migrating motor complex in healthy subjects and patients with irritable bowel syndrome. Neurogastroenterol Motil 20: 649-659, 2008.

10. McDonagh SC, Lee J, Izzo A and Brubaker PL: Role of glial cell-line derived neurotropic factor family receptor alpha 2 in the actions of the glucagon-like peptides on the murine intestine. Am J Physiol Gastrointest Liver Physiol 293: G461-G468, 2007.

11. Miki T, Minami K, Shinozaki H, et al: Distinct effects of glucose-dependent insulinotropic polypeptide and glucagon-like peptide-1 on insulin secretion and gut motility. Diabetes 54: 1056-1063, 2005.

12. Schirra J,Houck P, Wank U, Arnold R, Goke B and Katschinski M: Effects of glucagon-like peptide-1(7-36)amide on antro-pyloroduodenal motility in the interdigestive state and with duodenal lipid perfusion in humans. Gut 46: 622-631, 2000.

13. Schirra J, Nicolaus M, Roggel R, et al: Endogenous glucagon-like peptide 1 controls endocrine pancreatic secretion and antropyloro-duodenal motility in humans. Gut 55: 243-251, 2006.

14. Amato A, Cinci L, Rotondo A, Serio R, Faussone-Pellegrini MS, Vannucchi MG and Mulè F: Peripheral motor action of glucagon-like peptide-1 through enteric neuronal receptors. Neurogastroenterol Motil 22: e664-e203, 2010.

15. Körner M, Stöckli M, Waser B and Reubi JC: GLP-1 receptor expression in human tumors and human normal tissues: potential for in vivo targeting. J Nucl Med 48: 736-743, 2007.

16. Peng LH, Yang YS, Sun G and Wang WF: A new model of Constipation-predominant irritable bowel syndrome in rats. Shijie Huaren Xiaohua Zazhi 12: 112-116, 2004 (In Chinese).

17. Williams CL, Villar RG, Peterson JM and Burks TF: Stressinduced changes in intestinal transit in the rat: a model for irritable bowel syndrome. Gastroenterology 94: 611-621, 1988.

18. Gui XY, Pan GZ and Ke MY: Residual effect of cold-restraint stress on colonic motility in rats. Chin J Dig Dis 17: 94-96, 1997 (In Chinese).

19. Habold C, Reichardt F, Le Maho Y, et al: Clay ingestion enhances intestinal triacylglycerol hydrolysis and non-esterified fatty acid absorption. Br J Nutr 102: 249-257, 2009.

20. Winston J, Shenoy M, Medley D, Naniwadekar A and Pasricha PJ: The vanilloid receptor initiates and maintains colonic hypersensitivity induced by neonatal colon irritation in rats. Gastroenterology 132: 615-627, 2007.

21. Al-Chaer ED, Kawasaki M and Pasricha PJ: A new model of chronic visceral hypersensitivity in adult rats induced by colon irritation during postnatal development. Gastroenterology 119: 1276-1285, 2000.

22. Appleyard CB and Wallace JL: Reactivation of hapten-induced colitis and its prevention by anti-inflammatory drugs. Am J Physiol 269: G119-G125, 1995.

23. Livak KJ and Schmittgen TD: Analysis of relative gene expression data using real-time quantitative PCR and the 2[-Delta Delta C(T)] method. Methods 25: 402-408, 2001.

24. Tolessa T, Gutniak M, Holst JJ, Efendic S and Hellstrom PM: Glucagon-like peptide-1 retards gastric emptying and small bowel transit in the rat: effect mediated through central or enteric nervous mechanisms. Dig Dis Sci 43: 2284-2290, 1998.

25. Näslund E, Bogefors J, Skogar S, et al: GLP-1 slows solid gastric emptying and inhibits insulin, glucagon, and PYY release in humans. Am J Physiol 277: R910-R916, 1999.

26. Nagell CF, Wettergren A, Ørskov C and Holst JJ: Inhibitory effect of GLP-1 on gastric motility persists after vagal deafferentation in pigs. Scand J Gastroenterol 41: 667-672, 2006.

27. Bozkurt A, Näslund E, Holst JJ and Hellström PM: GLP-1 and GLP-2 act in concert to inhibit fasted, but not fed, small bowel motility in the rat. Regul Pept 107: 129-135, 2002.

28. Brubaker PL, Drucker DJ, Asa SL, Swallow C, Redston M and Greenberg GR: Prolonged gastrointestinal transit in a patient with a glucagon-like peptide (GLP)-1- and -2-producing neuroendocrine tumor. J Clin Endocrinol Metab 87: 3078-3083, 2002. 